International Journal of Applied Linguistics \& English Literature

ISSN 2200-3592 (Print), ISSN 2200-3452 (Online)

Vol. 1 No. 4; September 2012

\title{
The Role of Age and Gender in the Choice of Address Forms:
}

\section{A Sociolinguistic Study}

\author{
Mahzad Mardiha (corresponding author) \\ Department of Foreign Languages, Sheikh-Bahaei University, Isfahan, Iran \\ E-mail: m.mardiha@yahoo.com
}

Received: 11-06- 2012

Accepted: 25-07- 2012

Published: 01-09- 2012

doi:10.7575/ijalel.v.1n.4p.173

URL: http://dx.doi.org/10.7575/ijalel.v.1n.4p.173

\begin{abstract}
The main objective of the present study is to investigate the impact of gender as well as age on the choice of forms of address in Persian. The hypothesis is that variation in the forms of address is related not only to gender of the interlocutors but also to the age of them. For this study, 30 university students- 15 males and 15 femalesparticipated in this process that all of them were asked to fill out a questionnaire presented in the appendix. The results of the data analysis indicate that both men and women use address forms of formality (Šoma) more frequently in addressing the older people from both genders that shows age is more significant than gender in determining the pronouns in address system of Persian.
\end{abstract}

Keywords: Address forms, Age, Gender, Persian language system

\section{Introduction}

\subsection{Background}

For a long time, linguists were only concerned with the form and structure of language apart from its social context and social factors influencing the language. This was obviously the case with structural linguistics. Even when Chomsky revolutionized the field of linguistics in the mid-1950s and early 1960s, his theory did not go beyond linguistic forms. He was preoccupied with the notions of grammatical competence, that is, the ability to produce well-formed sentences and to differentiate between grammatical and ungrammatical sentences. Therefore, American structuralists and transformationalists alike concentrated massively on linguistic forms isolated from context. They reiterated that the object of linguistic analysis should be idealized, decontextualized sentences. However, it is not enough just to have grammatical competency in one's native language. One should also know how language is used in society. So, from the beginning of the 1970s, linguists have become increasingly aware of the importance of context in the interpretation of sentences. In particular, sociolinguists have become interested in explaining why we speak differently in different social contexts. As Holmes (1992:1) asserts, "examining the way people use language in different social contexts provides a wealth of information about the way language works, as well as about the social relationships in a community." We use different styles in different social contexts; therefore, sociolinguistics is concerned with the relationship between language and the contexts in which it is used.

Context in the use of language is very crucial, for linguistic and social behavior not only has to be appropriate to the individual and his socio-economic background, but it also needs to be suitable for particular occasions and situations. In other words, language varies not only according to the social characteristics of the speaker but also according to the social context in which he finds himself. Levinson (1983: 54) asserts that "the single most obvious way in which the relationship between language and context is reflected in the structure of languages themselves is through the phenomenon of deixis." Among the categories of deixis, one that is directly related to this study is social deixis, which refers to social roles played by an individual in a speech event. Social deixis includes terms of address and honorifics.

Terms of address are linguistic forms that are used in addressing others to attract their attention or for referring to them in the course of a conversation. Address forms, as Murphy (1988) has elegantly put it, are socially driven phenomena. In other words, linguistic forms that are used to address others can mirror the complex social relations of individuals in a speech community (Paulston, 1976; Trudgill, 1983; Chaika, 1982). It is also 
maintained that the best place to look for a correspondence between language and society in the grammar of a language is in the pronouns and forms of address. Therefore, address forms have been of great interest to sociolinguists, anthropologists, and social psychologists because these forms can conspicuously manifest the relationship between language and society.

Brown and Yule (1989: 54) argue that "in different social contexts different terms of address will be used."Consider, for example, the distribution of tu/vous pronouns in French (cf. Brown and Gilman, 1960). As Lyons (1977) points out, the terms of address used by a social inferior to a social superior may be different from those between peers, as in vocative terms like "Sir" or "Doctor" or "My Lord" (in the courtroom). In Persian, as in many other languages (e.g. French, Italian, Spanish, German, and Russian), speakers have to make a choice between two forms of 'you': (i) the deferential 'you', and (ii) the familiar 'you'. The deferential 'you' is used when an asymmetrical relationship exists between the dyads in a speech event, that is, when the addressee is in a superior social position or when the speaker does not have a sufficiently close personal relationship with the addressee. The familiar 'you', on the other hand, is used when an intimate relationship exists between the speaker and the addressee, or when the addressee is in a subordinate position. The deferential 'you' in Persian is /Šoma/ and the familiar 'you' is /To/. Forms of address in diverse languages have been studied from a various point of view (see, for example, Bates and Benigni, 1975; Brown and Gilman, 1960; Brown and Ford, 1961; Chandrasekhar, 1970; Cintra, 1972; Paulston, 1976; Ostor, 1982; Parkinson, 1982; Philipsen and Huspeck, 1985; Braun, 1988; MuÈ hlhaÈ usler and Harre, 1990; Oyetade, 1995; Martiny, 1996). However, many researchers have been mainly concerned with variation in the forms of address according to the social characteristics of the language users and the relationship between interlocutors. As an example, Brown and Levinson (1979, cited in Wardhaugh, 1993: 332-333), postulate that "T/V usage is tied primarily to kinds of social relationship." The significance of the present study, however, lies in the fact that it deals primarily with the role of social characteristics of interlocutors in the choice of forms of address. In this study, two important variables, namely gender and age, are investigated. These two variables are crucial in determining our linguistic choices. For instance, the choice of the pronoun /To/ in Persian indicates intimacy; whereas, /Šma / shows formality. As Holmes (1992: 247) states, "many factors may contribute in determining the degree of formality or intimacy between people - relative age, sex, social roles, whether people work together, or are members of the same family and so on."

\subsection{Research Problem}

Variables such as age, gender, social class, education, and so on may contribute to determine the choice of linguistic forms that are used in addressing others in Persian. Therefore, it is hypothesized that one's use of forms of address depends largely on social context and sociolinguistic parameters such as age and gender of the interlocutors. Based on the foregoing discussion, the present study strives to answer the following research questions:

1. What is the role of social factors in the choice of address forms?

2. Is there any relationship between the sociolinguistic variables such as age and gender of interlocutors and variation in the use of forms of address?

\subsection{Purpose of the Study}

The present study aims at exploring the sociolinguistic norms of address in Persian. It will shed light on the rules and patterns of address that people employ in their interactions with others in using of the intimate or formal pronouns such as $\mathrm{T}(\mathrm{To})$ and $\mathrm{V}$ ( Šma) according to the age and gender of the addresses.

\subsection{Significance of the Study}

Studies on the topic of the sociolinguistic rules of address don't tackle the whole theory of socio-linguistic rules of address. This study will attempt to examine the rules and frequencies of address forms like pronouns " $T$ " and "V" between Persian speakers. The significance of the study lies in the fact that it deals primarily with the role of social factors in the choice of forms of address .Important variables, namely age and gender of interlocutors are investigated. In addition, considering the limited studies on this field, by doing this study, the researcher hopes that it will encourage other students and researchers to do more studies on address form variations according to other sociolinguistic parameters such as social class, education, religion, etc.

\subsection{Limitation of the Study}

In order to perceive specific subjects and objects of investigation, researcher ought to limit them to certain scope, 
reference, respondents, and samples of population. In this research, what the researcher is going to do is under the study of sociolinguistics. Furthermore, Address forms used mean selection of certain linguistic form by the relation between the speaker and his/her addressee, like personal pronouns. Persian, has two personal pronouns for singular address, "To" the familiar or intimate "you" and "Šoma" the deferential or formal "you"( historically the second person plural but now also used as second person singular). Other forms of address such as personal names, title terms, kinship terms, etc have been excluded from the research because of limited scope of the study. (It will be discussed more in next sections). Moreover, the used address forms are limited to formal setting and population of the data is limited to 30 participants who are 15 men and 15 women of university students and represent the Persian culture and sociolinguistic norms as well as possible.

\subsection{Organization of the Study}

This research report consists of five sections. The first section is the introduction, which includes the background, research problem, purpose, significance, limitation and organization of the study. The second section is the review of related literatures, which consists of the main related theories, and related studies. The next section is the methodology that has been used in this study. Then the findings of the research will be discussed in the fourth section. Finally, the last section is the conclusion of the whole research.

\section{Review of Literature}

According to Brown and Gilman (1960), the pattern of address may change in time depending on special circumstances, and the variation in the forms of address is determined by the degree of relationship between the interlocutors. They point out that most people in speaking and writing English use only one pronoun of address: 'you' to many persons and 'you' to one person .The pronoun 'thou' is limited nowadays to prayers and native poetry, but in the past it was the form of familiar address to a single person. In French, German, Italian, Spanish and other languages, there are still two active pronouns of address that begin with the Latin 'tu' and 'vous' and for convenience they propose to use the symbols ' $T$ ' and ' $\mathrm{V}$ '. They believe that the selection of ' $T$ ' and ' $\mathrm{V}$ ' depends on the relationship existing between the speaker and the addressee. They relate the pronouns ' $\mathrm{T}$ ' and ' $\mathrm{V}$ ' to two dimensions: power and solidarity. They suggest that a man may vary his pronoun style from time to time to express his moods and attitudes.

Brown and Ford (cited in Hymes, 1964) refer to the main options of address in American English as the choice between use of first name[FN] and use of a title with the last name[TLN]. In their study of address in American English, they begin by describing the norms of American address, then they point out a certain pattern in these norms which is to be found in the forms of address of all languages known to us. They also refer to other characterizations of the several common forms besides first name and title with last name such as: title without name (including Sir, Madam, Ma'am, and Ms.), last name alone, multiple names in which a speaker may use more than one form of the proper name for the same addressee, sometimes saying [TLN], sometimes different forms either [FN] or nicknames. They mention that the pattern applies to more than names, titles and pronouns. It follows greetings which themselves were quite varied including: Hi, Good morning, Hello, etc.

According to Wardhaugh (1986) "How we say something is at least as important as what we say." He points out that when we speak ,we must constantly make choices of many different kinds: what we want to say, how we want to say it, and words and sounds that best unite the 'what' with the 'how'. He also points out that the content and the form of address are quite inseparable. Certain linguistic choices a speaker makes indicate the social relationship that the speaker perceives to exist between him / her and the listener. According to Wardhaugh (1986), many languages have a distinction corresponding to the tu - vous ( $t / v)$ distinction in French, where grammatically there is a Singular' you'tu (T) and a plural you vous (V). The (T) form is sometimes described as the familiar form and (V) form as 'polite one'. Other languages with similar T/V distinction are Latin (tu /vous), Russian (ty /vy), Italian (tu / lei), German (du / sie), Swedish (du / ni) and Greek (esi / esis). English itself once had a 'thou/you' distinction.

Braun (1988) points out that normal words and expressions serve as forms of address. They have lexical meanings and when used for addressing people, these forms can be said to mean one thing or another according to their lexicon definition. He also points out that the semantics of address variants can be a complicated matter when several kinds of meanings being involved.

According to Al-Bainy (1996), speaking to others usually needs thinking of the beginning of the conversation for a while. The beginning is usually a form of address which he defines as "a certain word that is used to draw the attention of the addressee." 
Keshavarz (2001) defines forms of address as "the linguistic forms that are used in addressing others to attract their attention or to refer to them in the course of a conversation". According to the same author, linguistic forms that are used to address others can mirror the complex social relations of individuals in a speech community. These forms can also reflect the relationship between language and society.

In a study of bilingual creativity in Chinese English, Zhang (2002) stresses the importance of address term studies and specifies that these terms play an important role in conveying cultural messages, especially with respect to the status of interlocutors and power relation between them.

Wardhaugh (2006) also notes that a variety of social factors usually governs our choices of terms. Among these social factors are the particular occasion, the social status or rank of the other, sex, age, family relationships, occupational hierarchy, transactional status, such as a doctor-patient relationship or priest-penitent, race, and the degree of intimacy.

In a study, Afful (2006) makes a distinction between 'address terms' and 'reference terms' and uses the former as the linguistic expression by which an addresser designates an addressee in a face-to-face encounter. With reference to the social functions of address terms, Afful (2006) also notes that sociolinguistic studies on address terms tend to show that they are contingent on a number of factors such as socioeconomic status, age, sex, the relationship that exists between interlocutors and the domains of a communicative encounter.

\subsection{Types of Forms of Address}

In general, forms of address are correlated with the social status and interpersonal relationships between the addressee and addresser. The attempt of the authors concerning categorization of address forms in Modern Persian can be regarded as a pioneering effort to demonstrate the vast lingual potentiality of this language regarding multiplicity of interlocutory expressions on the one hand and the changeability and enrichment of these terms especially during the last three decades on the other. Forms of address consist of different types such as:

1. Interjections

2. Personal names:

- First name (FN)

- Last name (LN)

- Full formal name: first and last name (FLN)

3. Title terms:

- Title plus first name

- Title plus last name

- Title only

4. Religious address terms

5. Occupation-Bound terms

6. Kinship or family terms:

- Kin term

- Kin term plus first name

7. Honorifics or terms of formality

8. Terms of intimacy

9. Personal pronouns

- Tu (To)

- Vous (Šoma)

10. Descriptive phrases

11. Zero address terms

Each category has its special usage for particular people and under certain conditions in Persian language that some of them will be discussed very briefly in the following:

The abundance and the frequency of the application of honorifics in Persian language reveal the importance of courtesy in this language. It sounds that courteous and humble interaction is a striking feature of Persian address system. It also shows that Persian speakers are very careful about their face work.

Another distinctive feature of Persian is revealed in the use of kinship address terms. Persian is found to be very dependent on the family relations and this is especially notable in reverse addressing or using kinships for non-relatives.

Restrictions in the use of personal names and pronominal on the one hand and the tendency to use general and 
occupational titles, honorifics and terms of formality make it certain that the sense of formality is also another striking feature of Persian culture and language in general and address terms in particular. Developing new terms and banding some others over time which is the characteristic of dynamic languages show that Persian language is dynamic enough to comply with the socio-cultural changes in its speech communities.

To address one another, Persian interlocutors are likely to make use of different techniques. This open variety provides the Persian speakers with an extensive range of terms to address the recipients. Employment of a proper address term is affected by factors as age, gender, personality, social status, religious orientation, family relationship, degree of respect, familiarity, formality and intimacy between the interlocutors.

One more point which indirectly accounts for the long history of Persian language and its interaction with other cultures is the existence of loanwords from other languages. As a result, Persian speakers may use terms from other relevant oriental languages like Arabic, Turkish, and Mongolian in their expression. The borrowed lexemes like/âghâ/ (Mr.), /khânom/ (Ms), and /khân/ (Mr., your Excellence) are examples of these loan vocabularies which are frequently used in Persian.

In general, the overall examination of the address terms makes it clear that Persian address terms are relatively formal and culturally, socially and politically loaded. Moreover, the stress in using honorifics, the special employment of kinship terms, the development of religious terms and the abandonment of the terms related to aristocracy stand for socio-cultural and sociopolitical function of the address terms in modern Persian. Finally it should be mentioned that due to the limits for the size of an article, this paper is limited to pronouns only. Persian has two personal pronouns for singular address, $\mathrm{T}$ (To), the familiar or intimate 'you' and V (Šoma), the deferential or formal 'you'( historically the second person plural but now also used as second person singular).

Most European languages also have two forms of the second person singular pronoun i.e. 'you' (informal) and 'you' (formal), for example languages such as French (tu/vous), German (du/sie), Swedish (du/ni), Italian (tu/lei), and English that once used to have both forms (you/thee) like Persian are using a T/V pronominal system. Choosing between formal and informal pronouns in such systems is socially motivated and represents people's relationship to each other in a particular way.

\subsection{Reciprocal vs. Non-Reciprocal}

This pronominal system can be reciprocal or non-reciprocal.

In reciprocal system both persons, who are talking to use the same format such as:

- V-V system: Formal reciprocal system that reflects distance, respect and equality.

- T-T system: Informal reciprocal system that reflects equality and closeness.

$>$ In non-reciprocal system, person gives one kind of pronoun and receives another kind of pronoun such as :

- T-V system: Non-reciprocal system that one person has a higher status than the other. V is offered as a sign of respect; $T$ is offered as a sign of affection. In fact, this system reflects the inequality in status.

Pronominal system of Persian language also, as mentioned above, has a T/V system that can be changed in different situations according to the various sociolinguistic factors such as age, gender, education, social class, etc related to the interlocutors. In this paper, scope of study has been limited to the examination of personal pronouns according to the age and gender of the interlocutors to determine the effect of these factors on the pronominal system of the Persian language.

\section{Methodology}

This paper presents the study of sociolinguistic variation. It aims at finding out the role of social factors that influence the usage of the formal or the informal pronouns while addressing other people. Quantitative and qualitative methods have been applied in order to investigate how addressers use personal pronouns according to the age and gender of their addressees.

\subsection{Participants}

The subjects of this study were 30 Persian speakers - 15 males and 15 females-who were university students. On the basis of the information elicited in the first part of the questionnaire, the subjects were categorized into two groups according to their gender (male vs. female).

\subsection{Material}




\section{International Journal of Applied Linguistics \& English Literature}

ISSN 2200-3592 (Print), ISSN 2200-3452 (Online)

Vol. 1 No. 4; September 2012

The data for this study were gathered by means of a questionnaire (appendix) prepared and given to each of the participants. The questionnaire consisted of two main parts. Part one aimed at eliciting personal information about the subjects to make the task of categorization possible, and in part two, items were included that asked the subjects to choose the address forms they usually use for interaction with specified addressees of different ages and genders.

\subsection{Procedure}

The questionnaire was administered by the researcher according to a similar case in another research of address forms "sociolinguistic competences in the use of Colombian pronouns of address" and was given to the participants separately and they were asked to answer the questionnaire. They were given an oral explanation to elaborate more on what they were asked to do and to explain more about the goals of the research to the participants in order to gain their cooperation and assistance. After the data were gathered, the questionnaires were examined and classified and the number of $\mathrm{T}$ (to) and V (Šoma) cases were counted according to the different age and gender groups.

\subsection{Data Analysis}

The data gathered and presented in the result section to be explained here. Table 1 , in the next section consists of two column which vertical column refers to the age of interlocutors and horizontal column that refers to their gender. In this table, / T / refers to the cases that addressers use the pronoun (To), and /V/ refers to the cases that addressers use the pronoun (Šoma) in interaction with their addressees. /Same Gender/ refers to the cases that men $/ \mathrm{M} \rightarrow \mathrm{M} /$ or women $/ \mathrm{F} \rightarrow \mathrm{F} /$ address the people of their own gender and /Different Gender/ refers to the cases that men $/ \mathrm{M} \rightarrow \mathrm{F} /$ or women $/ \mathrm{F} \rightarrow \mathrm{M} /$ address the people of the opposite gender of his/her own. In table 2 , percentage of the number of using $/ \mathrm{T} /$ and $/ \mathrm{V} /$ in each case was calculated and finally by comparing the results from each part, the conclusion of this study was made.

\section{Results}

Table 1

\begin{tabular}{|c|c|c|c|c|c|c|c|c|}
\hline & \multicolumn{4}{|c|}{ Same Gender } & \multicolumn{4}{|c|}{ Different Gender } \\
\hline \multirow{3}{*}{ Gender } & \multicolumn{2}{|c|}{ Part 1} & \multicolumn{2}{|c|}{ Part 2} & \multicolumn{2}{|c|}{ Part 3} & \multicolumn{2}{|c|}{ Part 4} \\
\hline & \multicolumn{2}{|c|}{$\mathrm{M} \rightarrow \mathrm{M}$} & \multicolumn{2}{|c|}{$\mathrm{F} \rightarrow \mathrm{F}$} & \multicolumn{2}{|c|}{$\mathrm{M} \rightarrow \mathrm{F}$} & \multicolumn{2}{|c|}{$\mathrm{F} \rightarrow \mathrm{M}$} \\
\hline & $\mathrm{T}$ & $\mathrm{V}$ & $\mathrm{T}$ & $\mathrm{V}$ & $\mathrm{T}$ & $\mathrm{V}$ & $\mathrm{T}$ & $\mathrm{V}$ \\
\hline Younger & 51 & 18 & 60 & 7 & 40 & 20 & 52 & 19 \\
\hline $\begin{array}{c}\text { Same } \\
\text { Age }\end{array}$ & 32 & 9 & 43 & 4 & 20 & 12 & 15 & 31 \\
\hline Older & 23 & 52 & 32 & 47 & 19 & 53 & 17 & 59 \\
\hline
\end{tabular}


International Journal of Applied Linguistics \& English Literature

ISSN 2200-3592 (Print), ISSN 2200-3452 (Online)

Vol. 1 No. 4; September 2012

Table 2

\begin{tabular}{|c|c|c|c|c|c|c|c|c|}
\hline & \multicolumn{4}{|c|}{ Same Gender } & \multicolumn{4}{|c|}{ Different Gender } \\
\hline \multirow{3}{*}{ Gender } & \multicolumn{2}{|c|}{ Part 1} & \multicolumn{2}{|c|}{ Part 2} & \multicolumn{2}{|c|}{ Part 3} & \multicolumn{2}{|c|}{ Part 4} \\
\hline & \multicolumn{2}{|c|}{$\mathrm{M} \rightarrow \mathrm{M}$} & \multicolumn{2}{|c|}{$\mathrm{F} \rightarrow \mathrm{F}$} & \multicolumn{2}{|c|}{$\mathrm{M} \rightarrow \mathrm{F}$} & \multicolumn{2}{|c|}{$\mathrm{F} \rightarrow \mathrm{M}$} \\
\hline & $\mathrm{T}$ & $\mathrm{V}$ & $\mathrm{T}$ & $\mathrm{V}$ & $\mathrm{T}$ & $\mathrm{V}$ & $\mathrm{T}$ & $\mathrm{V}$ \\
\hline Younger & $\% 74$ & $\% 26$ & $\% 89 / 5$ & $\% 10 / 5$ & $\% 66$ & $\% 33$ & $\% 73$ & $\% 27$ \\
\hline $\begin{array}{l}\text { Same } \\
\text { Age }\end{array}$ & $\% 78$ & $\% 22$ & $\% 91 / 5$ & $\% 8 / 5$ & $\% 62 / 5$ & $\% 37 / 5$ & $\% 32$ & $\% 68$ \\
\hline Older & $\% 30$ & $\% 70$ & $\% 40 / 5$ & $\% 59 / 5$ & $\% 26$ & $\% 74$ & $\% 22$ & $\% 78$ \\
\hline
\end{tabular}

Table 3

\begin{tabular}{|c|c|c|c|c|c|c|c|c|}
\hline Frequency & \multicolumn{4}{|c|}{ Same Gender } & \multicolumn{4}{|c|}{ Different Gender } \\
\hline \multirow{3}{*}{ Gender } & \multicolumn{2}{|c|}{ Part 1} & \multicolumn{2}{|c|}{ Part 2} & \multicolumn{2}{|c|}{ Part 3} & \multicolumn{2}{|c|}{ Part 4} \\
\hline & \multicolumn{2}{|c|}{$\mathrm{M} \rightarrow \mathrm{M}$} & \multicolumn{2}{|c|}{$\mathrm{F} \rightarrow \mathrm{F}$} & \multicolumn{2}{|c|}{$\mathrm{M} \rightarrow \mathrm{F}$} & \multicolumn{2}{|c|}{$\mathrm{F} \rightarrow \mathrm{M}$} \\
\hline & $\mathrm{T}$ & $\mathrm{V}$ & $\mathrm{T}$ & $\mathrm{V}$ & $\mathrm{T}$ & $\mathrm{V}$ & $\mathrm{T}$ & $\mathrm{V}$ \\
\hline Younger & $0 / 48$ & $0 / 23$ & $0 / 44$ & $0 / 12$ & $0 / 50$ & $0 / 23$ & $0 / 61$ & $0 / 17$ \\
\hline $\begin{array}{l}\text { Same } \\
\text { Age }\end{array}$ & $0 / 3$ & $0 / 11$ & $0 / 31$ & $0 / 06$ & $0 / 25$ & $0 / 14$ & $0 / 17$ & $0 / 28$ \\
\hline Older & $0 / 22$ & $0 / 66$ & $0 / 23$ & $0 / 81$ & $0 / 24$ & $0 / 62$ & $0 / 20$ & $0 / 54$ \\
\hline
\end{tabular}

\section{Discussion}

In this study, the subjects were asked to choose one of the two address forms /To/ and /Šma/ that they usually use for interaction with specified addressees, according to their age and gender as described previously. It must be remembered that Persian, unlike English, has two personal pronouns /To/ and /Šoma/ for a singular addressee. The familiar / To/ is used for addressing intimate friends and colleagues, and also inferiors in terms of age and authority. The deferential /Šoma/, on the other hand, is reserved for superiors and/or equals in different situations. The items included in the questionnaire aimed at investigating the effect of the formality of context as well as age and gender of the interlocutors on the choice of appropriate forms of address. The results are discussed below in four sections.

5.1 The use of $/ \mathrm{To} /$ and /Šma/ by men in addressing the people of their own gender $(\mathrm{M} \rightarrow \mathrm{M})$ in three age categories: In first part of the tables in previous section, the results show the percentage of using the two forms 
of /To/ and /Šoma/ by men in addressing the other men. Comparison of the total percentages of the use of these address forms shows that men use different forms of address in interaction with men addressees according to their age. It shows that as the age gap between the interlocutors decreases, the use of /Šoma/ also declines. For instance, the percentage of use of /Šma/ in addressing the younger men was about 26 percent; whereas, this percentage increased to 70 percent in addressing older men. In fact, a total look at the data would seem to indicate that men addressers have a tendency to address younger men or men of their own age with the intimate pronoun /To/ and older men with the formal pronoun/Šoma/.

5.2 The use of $/ \mathrm{To} /$ and /Šma/ by women in addressing the people of their own gender $(\mathrm{F} \rightarrow \mathrm{F})$ in three age categories: In the second part of the tables again, the percentage of the use of two forms of $/ \mathrm{To} / \mathrm{and} / \mathrm{S}$ oma/ by women in addressing the other women is shown. Comparison of the total percentages of the use of $/ \mathrm{To} / \mathrm{and}$ /Šoma/ shows that women also use different address forms in addressing other women according to their age. It shows that as age gap between women interlocutors decreases, the use of /Šoma/ between them also declines. For instance, the percentage of the use of /Šma/ in addressing older women was about 59/5 percent; whereas, this percentage decreased to $10 / 5$ and $8 / 5$ percent in addressing the younger women and the women of their own age respectively, that these results would seem to indicate that women addressers like men, have a tendency to address the younger women or women of their own age with intimate and familiar forms of address /To/ and the older women with the deferential and formal forms of /Šoma/.

5.3 The use of /To/ and /Šoma/ by men in addressing the people of the opposite gender of their own $(\mathrm{M} \rightarrow \mathrm{F})$ in three age categories: In third part of the tables, the results show the percentage of the use of two forms of $/ \mathrm{To} /$ and /Šoma/ by men in interaction with the women from three different age categories. This comparison of the total percentages of the use of /To/ and /Šoma/ shows that men in interaction with younger women or women of their own age, use the intimate form of /To/ more than /Šoma/ but in addressing the older women use the formal form of /Šoma/ more than /To/ that these findings would point to the fact that age is more significant than gender in determining forms of address. For instance, the percentage of use of /Šoma/ in addressing older women was over 74 percent; whereas, this percentage decreased to 33 and $37 / 5$ percent in addressing the younger women or women of their own age, respectively.

5.4 The use of /To/ and /Šoma/ by women in addressing the people of the opposite gender of their own $(\mathrm{F} \rightarrow \mathrm{M})$ in three age categories: In fourth part of the tables, the last one, the percentage of the use of two forms of $/ \mathrm{To} /$ and /Šoma/ by women in addressing the men is shown. Comparison of the total percentages of the use of these pronouns in this part indicates some differences from the third part. The results show that women use different address forms in addressing men according to their age. Women also in addressing younger men choose the familiar form of /To/ more than /Šoma/ but in addressing men of their own age or older men, they use the formal form of /Šoma/ more in their interactions. For instance, in addressing younger men, the percentage of the use of /Šoma/ was about 27 percent; whereas, this percentage increased to 78 and 68 percent in addressing older men or men of their own age, respectively. Here again, it can be concluded that age is a determining factor in the choice of these two pronouns for addressing different genders.

\section{Conclusion}

The findings of the present study support the view that language is sensitive to social and extra-linguistic variables such as age, gender, social class, education, etc. As Montgomery (1993: 101) asserts any given instance of language is inextricably bound up with its sociolinguistic situation. The results of the data analysis in this study indicate that age and gender of addressees, as the sociolinguistic variables, have a significant role as a determining variable affecting the choice and use of pronouns of address in Persian. As a general conclusion, it can be drawn from this study that in the Iranian culture age, as a sociolinguistic variable, is more significant than gender. As discussed before, results show that men and women choose and use the formal form of address /Šoma/ in addressing the older people of their own gender which shows the superiority of age over gender of addressees. In the other part of the study, results also show that men address the older women with formal address form /Šoma/ while women use this formal pronoun in interaction with older men or men of their own age that this can somewhat confirm the claim made elsewhere (keshavarz, 1988) that in interaction with members of the opposite gender in the Iranian culture people tend to be more polite and deferential that this view can be observed about women in addressing men to some extent and of course not absolutely.

This particular finding may be associated to the principle that Brown and Gilman (1960) stated regarding the existence of vertical sociolinguistic parameters that acknowledged power, and horizontal parameters that expressed solidarity through the choice of pronouns. The use of V (Šoma) reveals that most of people actively 
International Journal of Applied Linguistics \& English Literature

ISSN 2200-3592 (Print), ISSN 2200-3452 (Online)

Vol. 1 No. 4; September 2012

acknowledge a particular status -of respect- to the elderly, by employing a special pronoun when addressing them. On the opposite direction, we see that the pronominal system establishes a relationship of power over younger people, for example, younger siblings and younger coworkers: In these cases, the data reported the favored use of T (To) in both men and women (Pearson .000, df 12 and Pearson .001, df 12 respectively). This fact can be interpreted as a perception of the semantics of $\mathrm{T}$ (To) as a means to exercise power and superiority over younger addressees, and the semantics of V (Šoma) as a way to acknowledge power or superiority. This fact agrees with Brown and Gilman's proposal (1960), which expressed that the power of semantics is non-reciprocal, and is reflected in the choice of the pronouns of address. In the same way, horizontal sociolinguistic parameters of solidarity were revealed by the participants, when declaring a preference for $\mathrm{T}$ (To) at the time of addressing people of the same age and same gender. This may lead us to think the present status of the Iranian speech community actually depicts T (To) and V (Šoma) with expanded semantics (Uber,1985), that can be considered as an indication that the different generations of the Persian people are going through a process of change in the criteria regarding the use of pronouns in address system of Persian.

\section{References}

Afful, Joseph B. A. (2006b). Non-kinship Address Terms in Akan. A Sociolinguistic Study of Language Use in Ghana. Journal of Multilingual and Multicultural Development, 27, 4: 275-289.

Bernstein, B. (1972). Social Class, Language and Socialization. In Giglioli (1972).

Braun, F. (1988). Terms of Address. Berlin: Mouton de Gruyter.

Brown, P. (1980). How and why are women more polite: some evidence from a Mayan Community. In

McConnellGinet, S., Borker, R. \& Furman, N. (eds.): Women and Language in Literature and Society. New York: Praeger.

Brown, R. \& Ford, M. (1961). Address in American English. Journal of Abnormal and Social Psychology, 62 , 375-385.

Brown, R. \& Ford, M. (1964). Address in American English. In: Hymes, Dell H. (ed.): Language in Culture and Society. New York: 234-244.

Brown, R. \& Ford, M. (1966). Address in American English. In Hymes, Dell (ed.): Language in Culture and Society. New York: Harper and Row.PP.234-44.

Brown, R. \& Gilman, A. (1960). The Pronouns of Power and Solidarity. In: Sebeoki, Thomas A. (ed.): Style in Language. Cambridge, MA: 253-276.

Chandrasekhar, A. (1970). Personal pronouns and pronominal forms in Malayalam.

Coates, J. (1993). Women, Men and Language. 2nd ed. London: Longman.

Fishman, J.A. (1968). Readings in the Sociology of Language. The Hague: Mouton.

Holmes , J. \& Pride J.B . (1972). Sociolinguistics: Selected Reading. London: Hazel Watson \& Viney ltd.

Holmes, J. (1992). An Introduction to Sociolinguistics. London: Longman.

Holmes, J. (1995). Women, Men and Politeness. Longman, London and New York.

Hymes, D.( 1964 ). Language in Culture and Society: A Reader in Linguistics and Anthropology .New York: Harper \& Row Publishers.

Hymes, Dell H. (1967). Models of Interaction of Language and Social Setting. Journal of Social Issues 23, 2 : $8-28$.

Keshavarz, M.H.(1988). Forms of Address in Post-revolutionary Iranian Persian. A Sociolinguistic Analysis. Language in Society, 17, 565-575.

Labov, W.(1970).The Study of Language in its Social Context. Studium Generale, vol 23, 30 - 87.

Levinson, S.C. (1983). Pragmatics. Cambridge: Cambridge University Press.

Ostor, A. (1982). Terms of Address and Hungarian Society. Language Sciences 4 (1), 55-69.

Oyetade, S.O. (1995). A Sociolinguistic Analysis of Address Forms in Yoruba. Language in Society 24 (4), 515-535.

Parkinson, D.B. (1982). Terms of Address in Egyptian Arabic. Unpublished Ph.D. dissertation, University of Michigan.

Trudgill, P. (1983). Sociolinguistics: An Introduction to Language and Society. Harmondsworth: Penguin. Wardhaugh, R. (2006). An Introduction to Sociolinguistics. 5th ed. Oxford.

Zhang, H. (2002). Bilingual Creativity in Chinese English. Ha Jin's in the pond. World Englishes 21, 2: $305-315$. 
International Journal of Applied Linguistics \& English Literature

ISSN 2200-3592 (Print), ISSN 2200-3452 (Online)

Vol. 1 No. 4; September 2012

\section{Appendix}

Please mention your sex and age and answer the questionnaire carefully by choosing A, B, or C.

Sex:

Age:

What pronoun do you use towards?
A. To $/ / 2$
B. Shoma / شما /
C .Don't have / Don't know /

\begin{tabular}{|c|c|c|c|c|}
\hline \multicolumn{2}{|l|}{ 1. Your grandmother } & $\mathrm{A}$ & $\mathrm{B}$ & $\mathrm{C}$ \\
\hline \multicolumn{2}{|l|}{ 2. Your grandfather } & $\mathrm{A}$ & $\mathrm{B}$ & $\mathrm{C}$ \\
\hline \multirow{2}{*}{ 3. Co-workers of your age } & Women & $\mathrm{A}$ & $\mathrm{B}$ & $\mathrm{C}$ \\
\hline & Men & A & $\mathrm{B}$ & $\mathrm{C}$ \\
\hline \multirow[t]{2}{*}{ 4. Older co-workers } & Women & $\mathrm{A}$ & $\mathrm{B}$ & $\mathrm{C}$ \\
\hline & Men & $\mathrm{A}$ & $\mathrm{B}$ & $\mathrm{C}$ \\
\hline \multirow[t]{2}{*}{ 5. Younger co-workers } & Women & A & $\mathrm{B}$ & $\mathrm{C}$ \\
\hline & Men & $\mathrm{A}$ & $\mathrm{B}$ & $\mathrm{C}$ \\
\hline \multirow[t]{2}{*}{ 6. Classmates of your age } & Women & $\mathrm{A}$ & $\mathrm{B}$ & $\mathrm{C}$ \\
\hline & Men & $\mathrm{A}$ & $\mathrm{B}$ & $\mathrm{C}$ \\
\hline \multirow[t]{2}{*}{ 7. Older classmates } & Women & $\mathrm{A}$ & $\mathrm{B}$ & $\mathrm{C}$ \\
\hline & Men & $\mathrm{A}$ & $\mathrm{B}$ & $\mathrm{C}$ \\
\hline \multirow[t]{2}{*}{ 8. Younger classmates } & Women & A & $\mathrm{B}$ & $\mathrm{C}$ \\
\hline & Men & $\mathrm{A}$ & $\mathrm{B}$ & $\mathrm{C}$ \\
\hline \multirow[t]{2}{*}{ 9. Relatives of your age } & Women & $\mathrm{A}$ & $\mathrm{B}$ & $\mathrm{C}$ \\
\hline & Men & A & $\mathrm{B}$ & $\mathrm{C}$ \\
\hline \multirow[t]{2}{*}{ 10. Older relatives } & Women & $\mathrm{A}$ & $\mathrm{B}$ & $\mathrm{C}$ \\
\hline & Men & A & $\mathrm{B}$ & $\mathrm{C}$ \\
\hline \multirow[t]{2}{*}{ 11. Younger relatives } & Women & A & $\mathrm{B}$ & $\mathrm{C}$ \\
\hline & Men & $\mathrm{A}$ & $\mathrm{B}$ & $\mathrm{C}$ \\
\hline \multicolumn{2}{|l|}{ 12. Your father } & $\mathrm{A}$ & $\mathrm{B}$ & $\mathrm{C}$ \\
\hline \multicolumn{2}{|l|}{ 13. Your mother } & A & $\mathrm{B}$ & $\mathrm{C}$ \\
\hline \multicolumn{2}{|l|}{ 14. Sister of your age } & $\mathrm{A}$ & $\mathrm{B}$ & $\mathrm{C}$ \\
\hline \multicolumn{2}{|l|}{ 15. Brother of your age } & A & $\mathrm{B}$ & $\mathrm{C}$ \\
\hline \multicolumn{2}{|l|}{ 16. Older sisters } & A & $\mathrm{B}$ & $\mathrm{C}$ \\
\hline \multicolumn{2}{|l|}{ 17. Older brothers } & A & $\mathrm{B}$ & $\mathrm{C}$ \\
\hline \multicolumn{2}{|l|}{ 18. Younger sisters } & $\mathrm{A}$ & $\mathrm{B}$ & $\mathrm{C}$ \\
\hline \multicolumn{2}{|l|}{ 19. Younger brothers } & $\mathrm{A}$ & $\mathrm{B}$ & $\mathrm{C}$ \\
\hline \multirow{3}{*}{ 20. Your own daughter } & Kid & $\mathrm{A}$ & $\mathrm{B}$ & $\mathrm{C}$ \\
\hline & Teen & $\mathrm{A}$ & $\mathrm{B}$ & $\mathrm{C}$ \\
\hline & Youth & $\mathrm{A}$ & $\mathrm{B}$ & $\mathrm{C}$ \\
\hline \multirow{3}{*}{ 21. Your own son } & Kid & A & $\mathrm{B}$ & $\mathrm{C}$ \\
\hline & Teen & $\mathrm{A}$ & $\mathrm{B}$ & $\mathrm{C}$ \\
\hline & Youth & $\mathrm{A}$ & $\mathrm{B}$ & $\mathrm{C}$ \\
\hline \multirow[t]{2}{*}{ 22. Any children } & Girls & $\mathrm{A}$ & $\mathrm{B}$ & $\mathrm{C}$ \\
\hline & Boys & $\mathrm{A}$ & $\mathrm{B}$ & $\mathrm{C}$ \\
\hline
\end{tabular}

